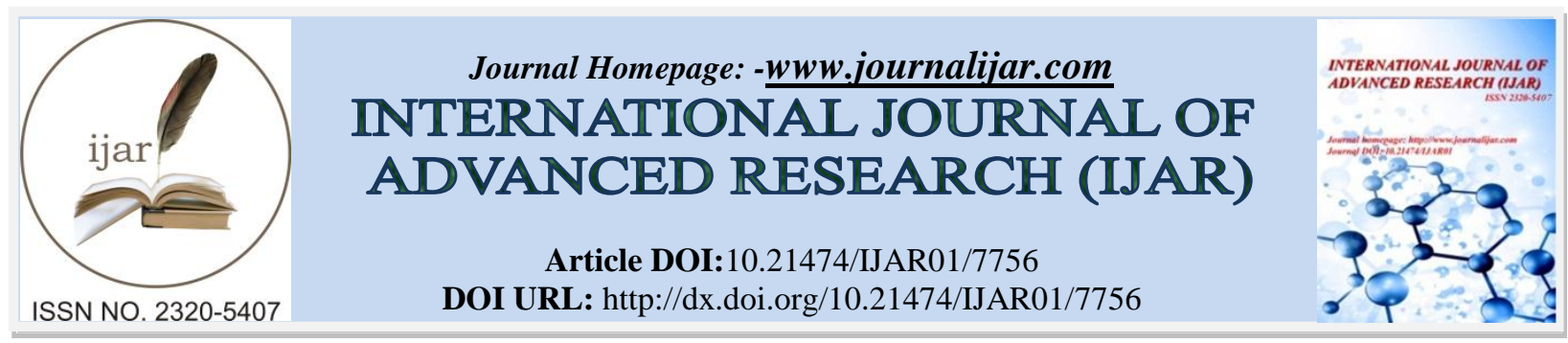

RESEARCH ARTICLE

\title{
EFFECTIVENESS OF WARM SHOWER ON PAIN PERCEPTION,AND LABOUR OUTCOME AMONGPRIMI PARTURIENT MOTHERS.
}

\author{
S. Suganthi and Dr. C. Susila.
}

$\mathrm{PhD}$ scholar MAHER,Principal, Billroth College of Nursing,Chennai.

\section{Manuscript Info}

Manuscript History

Received: $x x x x x x x x x x x x x x x$

Final Accepted: $x x x x x x x x x x x$

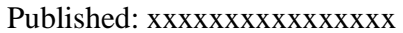

Keywords:-

perception, Warm shower, Labour outcome, Primi parturient mothers.

\begin{abstract}
Labour pain is an acute pain that cannot be compared to any other pain. An appropriate nursing intervention can change perception of the childbirth experience. Hence, the nurses need to involve actively in application of pain perception strategies to relieve pain during labour. Warm shower is a trusted and easily available therapy. The present study aim to assess the effectiveness of Warm shower on pain perception and labour outcome among 200 primi parturient mothers who fulfilled the inclusion criteria were selected for the study. Visual Analog Scale and partograph was used to assess the pain perception and labour outcome. The warm shower at 37-degree $\mathrm{C}$ was showered hourly 15 minutes from $4 \mathrm{~cm}$ to $8 \mathrm{~cm}$ cervical dilatation. The overall mean level of pain perception was 3.98 with SD 2.12. The unpaired $t$ $=10.081$ which is statistically significant at $\mathrm{p}<0.001$. With regard to Blood loss andExplusion of placenta, the mean was and 0.25 with SD of 1.32 and 0.43 respectively. The $t$ value for Blood loss and Expulsion of placenta was $t=6.486$ and $t=6.772$ respectively which is statistically significant at $p<0.001$. Thus hydrotherapy is an evidence based care for reducing the pain perception during labour and improving the labour outcome.
\end{abstract}

Copy Right, IJAR, 2018,. All rights reserved.

\section{Introduction:-}

Hydrotherapy formerly called as hydropathy and as water cure. It is a part of alternative medicine, particular in naturopathy, occupational therapy and physiotherapy that involves the use of water for pain relief and treatment. The safety and efficacy of hydrotherapy are well established for the first stage of labour. Hydrotherapy during labour improves cervical dilation, resolve labour dystocia and contribute to postpartum maternal satisfaction with child birth.The use of hydrotherapy during labour and birth should be guided by evidence based guideline.The researches have suggested regulation of water temperature to 36-37.5 degree Celsius, to prevent maternal and foetal hyperthermia and minimize the risk of premature respiration at the time of birth.

\section{Need for the study:}

Hydrotherapy reduces pain perception during the different stages of labour. It also provides psychological and physical relaxation. The theory behind water birth is that, since the baby has already been in the amniotic fluid sac for nine months, birthing in a similar environment is gentler for the baby and less stressful for the mother. Warm water causes the perineum to become more elastic and relaxed, reducing the incidence of severity of tearing and the 
need for episiotomy during labour. Warm water reduces the pain, improve circulation, promote relaxation, reduce muscle tightness and reduce the level of hormones secreted.

TANNER CJ, SWANSON M (2010) conducted the study to find out the effects of warm shower on anxiety, pain, and contraction dynamics during labour were assessed by using pretest, post test design.11 term women (mean age of 24.5 years) in spontaneous labour were immersed in 37 degrees of water for 1 hour. The result shows that pain decreased more for women with high base line pain than for women with low base line levels, cortisol levels decreased twice with $15 \mathrm{~min}$ of hydrotherapy for women with high base line than with those with low base line. The result shows that hydrotherapy during labour modify the psycho-physiological processes.

\section{Problem Statement}

A study to assess the effectiveness ofWarm showeron pain perception and selected variables of labour outcome during labour among primi parturient mothers at selected hospital, Chennai.

\section{Objectives Of The Study}

1. To assess the level of pain perception, and selected variables of labour outcome during labour after warm shower among primi parturient mothers in experimental and control group

2. To compare the level of pain perception,and selected variables of labour outcome of primi parturient mothers between the experimental and control group

3. To correlate the level of pain perception with selected variables of labour outcome in experimental and control group

4. To associate the level of pain perception, with selected variables of labour outcome of primi parturient mothers with their selected demographic variables.

\section{Research Methodology}

A Quasi experimental post test only design was adopted.The study was conducted with 200 primi parturient mothers (100 mothers for experimental group,sand 100 mothers for control group) were selected by convenient sampling and written consent from the mothers was obtained for the experimental group, warm shower was given for the mother(warm water $37^{\prime} \mathrm{c}$ was showered on mothers abdomen by using the shower jug containing $1000 \mathrm{ml}$ of water) for hourly $15 \mathrm{~min}$ from $4 \mathrm{~cm}$ dilatation till $8 \mathrm{~cm}$ dilatation. Pain perception was assessed by using visual analogue scale at $8 \mathrm{~cm}$ dilatation the labour outcome was monitored by using partograph and for the control group the hospital routine care was given and with the same tool pain perception and the labour outcome was monitored.

\section{Results And Discussion:-}

In the present study the investigator was interested to reduce the pain perception and improve the labour outcome through hydrotherapy. This promotes the release of endorphins and thereby reducing the pain perception.

It is proved that the demographic variables are statistically homogeneous.

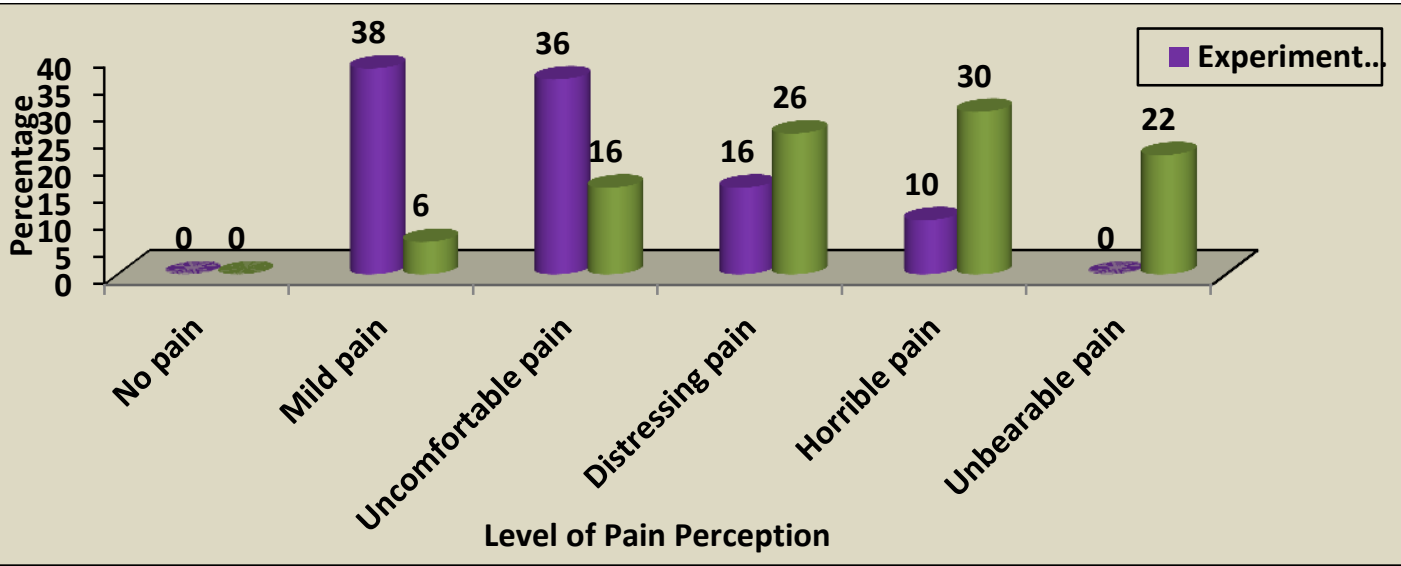

Fig 1:-Frequency and percentage distribution of post test level of pain perception and labour outcome among primi parturient mothers 


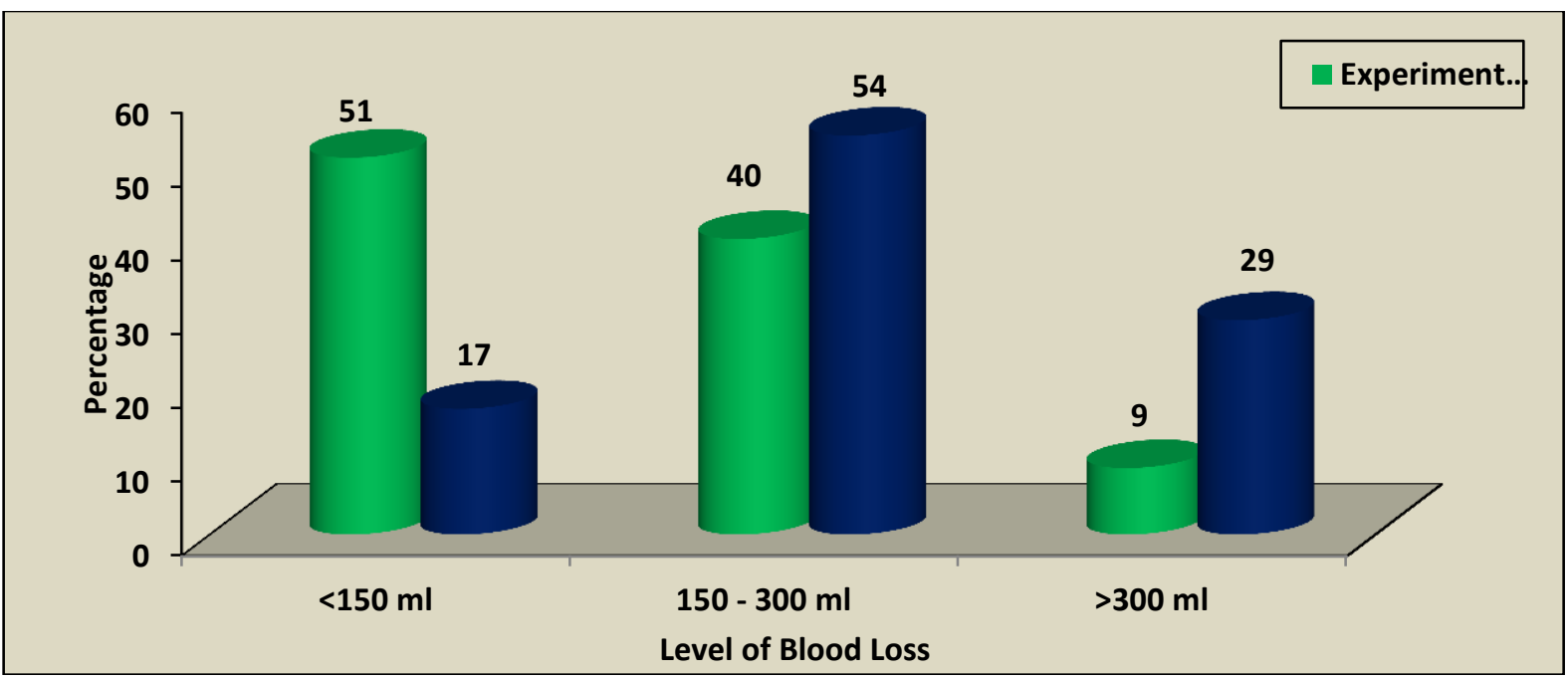

Fig 2:-Frequency and percentage distribution of post test level of Blood loss (Labour outcome) during labour among Primi parturient mothers in the experimental and control group.

Table 1:-Frequency and percentage distribution of post test level ofExpulsion of placenta (Labour outcome) during labour among Primi parturient mothers in the experimental and control group. $\quad(\mathbf{N}=\mathbf{1 0 0 + 1 0 0})$

\begin{tabular}{|c|c|c|c|c|c|c|c|c|c|}
\hline \multirow{2}{*}{ Group } & \multicolumn{2}{|c|}{$<5 \min$} & \multicolumn{2}{|c|}{$5-10 \min$} & \multicolumn{2}{|c|}{$10-15$ min } & \multicolumn{2}{|c|}{$>15$ min } & \multirow{2}{*}{$\begin{array}{l}\text { Chi-Square } \\
\text { Value }\end{array}$} \\
\hline & No. & $\%$ & No. & $\%$ & No. & $\%$ & No. & $\%$ & \\
\hline $\begin{array}{l}\text { Experimental } \\
\text { Group }(n=100)\end{array}$ & 10 & 10.0 & 56 & 56.0 & 28 & 28.0 & 6 & 6.0 & $\begin{array}{l}\chi^{2}=21.509 \\
\text { d.f }=3\end{array}$ \\
\hline $\begin{array}{l}\text { Control } \\
(\mathrm{n}=100)\end{array} \quad$ Group & 6 & 6.0 & 38 & 38.0 & 25 & 25.0 & 31 & 31.0 & $\begin{array}{l}\mathrm{p}=0.0001 \\
\mathrm{~S} * * *\end{array}$ \\
\hline
\end{tabular}

Table 2:-Comparison of post test level of pain perception score during labour among Primi parturient mothers between the experimental and control group. $\mathbf{N}=\mathbf{2 0 0}$

\begin{tabular}{|l|l|l|l|l|}
\hline Pain Perception & Mean & S.D & Mean Diff. & Unpaired ' $\mathrm{t}$ ' Value \\
\hline $\begin{array}{l}\text { Experimental Group } \\
\mathrm{n}=(100)\end{array}$ & 3.98 & 2.12 & 3.11 & $\begin{array}{l}\mathrm{t}=10.081 \\
\mathrm{p}=0.0001, \mathrm{~S} * * *\end{array}$ \\
\cline { 1 - 3 } Control Groups $\mathrm{n}=(100)$ & 7.09 & 2.23 & & \\
\hline
\end{tabular}

$* * * \mathrm{p}<0.001, \mathrm{~S}-$ Significant

Table 3:-Comparison of post testBlood loss (Labour outcome) score during labour among Primi parturient mothers between the experimental and control group.

$\mathbf{N}=\mathbf{2 0 0}$

\begin{tabular}{|l|l|l|l|l|}
\hline Blood loss & Mean & S.D & Mean Diff. & Unpaired ' $\mathrm{t}$ ' Value \\
\hline $\begin{array}{l}\text { Experimental Group } \\
\mathrm{n}=(100)\end{array}$ & 185.20 & 97.56 & \multirow{2}{*}{93.60} & $\begin{array}{l}\mathrm{t}=6.486 \\
\mathrm{p}=0.0001, \mathrm{~S} * * *\end{array}$ \\
\cline { 1 - 3 } Control Group $\mathrm{n}=(100)$ & 278.80 & 106.34 & & \\
\hline
\end{tabular}

$* * * \mathrm{p}<0.001, \mathrm{~S}-$ Significant

Table 4:-Comparison of post testExpulsion of placenta (Labour outcome) score during labour among Primi parturient mothers between the experimental and control group.

$$
\mathbf{N}=\mathbf{2 0 0}
$$

\begin{tabular}{|l|l|l|l|l|}
\hline Expulsion of placenta & Mean & S.D & Mean Diff. & Unpaired 't' Value \\
\hline Experimental Groupn $=(100)$ & 8.85 & 3.33 & 4.14 & $\mathrm{t}=6.772$ \\
$\mathrm{p}=0.0001, \mathrm{~S} * * *$
\end{tabular}

$* * * \mathrm{p}<0.001, \mathrm{~S}-$ Significant 
Table 5:-Correlation between post test level of pain perception and labour outcome among Primi parturient mothers in the experimental group.

$\mathbf{N}=\mathbf{1 0 0}$

\begin{tabular}{|c|c|c|c|}
\hline Variables & Mean & S.D & 'r' Value \\
\hline Pain perception & 3.98 & 2.12 & \multirow{2}{*}{$\begin{array}{l}\mathrm{r}=0.344 \\
\mathrm{p}=0.0001, \mathrm{~S}^{* * * *}\end{array}$} \\
\hline Blood loss & 0.25 & 0.43 & \\
\hline Pain perception & 3.98 & 2.12 & \multirow{2}{*}{$\begin{array}{l}r=-0.098 \\
p=0.334, N . S\end{array}$} \\
\hline Expulsion of placenta & 9.44 & 1.32 & \\
\hline
\end{tabular}

Association of post test level of pain perception and Labour outcome among primi parturient mothers with their selected demographic variables in the experimental group

In the Experimental group, it was found that there is a significant association with pain and the selected demographic variables- occupation, Habitant. There is also significant association with Blood loss and selected demographic variables- Education, Income. There is also significant association with Expulsion of placenta and selected demographic variables- age, type of family.

\section{Conclusion:-}

This study concluded that warm shower is cost effective, convenient, easy to deploy, non pharmacological approach to pain reduction. Thus warm shower during labour helps women to participate fully in birthing process, earn continuous midwife's support, feel cared, comforted and was effective in reducing the pain perception and improved the labour outcome among primi parturient mothers.

\section{References:-}

1. Aird IA, et al. Effects of intrapartum hydrotherapy on labour related parameters Journal of Obstetrical gynaecology. (1997) 37(2): 137-42.

2. Burns S. The Practice of Nursing Research. $4^{\text {th }}$ edPhiladelpia: W.B.Saunders Company. (1993)

3. Dutta D.C. Text book of Obstetrics including Perinatology and Contraception. $6^{\text {th }}$ ed. Calcutta: New Central Book Agency (P) Ltd. (2004)

4. .Jobstet Efficacy of warm shower during labour Journal of Nurse Midwifery(2013) 20 (2): 65 -72.

5. MallenPerzl,etal. Use of hydrotherapy during labour pain Journal of Gynaecology and Neonatal Nursing (2017) 35(5): $465-471$. 